\title{
Australasian Colorectal Surgeons in the Modern Era: The Rise of Social Media
}

\author{
Matija Radojcic $^{1, *}$, Michael Smits ${ }^{1}$, Nilmini Wickramasinghe ${ }^{2,3}$, Nathan Lawrentschuk ${ }^{1,4}$, Philip Smart ${ }^{1,5}$ \\ ${ }^{1}$ Department of Surgery, Austin Health, Melbourne, Australia \\ ${ }^{2}$ Health Informatics, Epworth HealthCare, Melbourne, Victoria, Australia \\ ${ }^{3}$ Faculty of Health, Deakin University, Melbourne, Victoria, Australia \\ ${ }^{4}$ UroRenal and Vascular Clinical Institute, Epworth HealthCare, Melbourne, Victoria, Australia \\ ${ }^{5}$ Gastrointestinal Clinical Institute, Epworth HealthCare, Melbourne, Victoria, Australia \\ *Corresponding author: matijaradojcic@gmail.com
}

\begin{abstract}
Background: Social media encompasses multiple forms of electronic communication where users create online communities to share ideas, information and other content. Social media use has grown rapidly, becoming important in surgical practice by providing opportunities for medical education and interaction with patients and colleagues. No study to date has looked at the uptake and prevalence of social media use amongst colorectal surgeons in Australia and New Zealand (NZ). Aim: To assess the use of websites and social media by all practicing colorectal surgeons in Australia and NZ. Methodology: All members of the Colorectal Surgical Society of Australia and NZ (CSSANZ) were identified. Comprehensive searches of websites and social media platforms (Facebook, Twitter, LinkedIn, YouTube and ResearchGate) were undertaken to record the presence of a private website or social media account. Factors that were examined included the sex of the surgeon, years in practice and geographical location of the surgeon. Results: There were 230 practicing colorectal surgeons in Australia and NZ as of December 2017. $80 \%$ of surgeons had a private website, of which $20 \%$ were 'single surgeon' websites. $68 \%$ of surgeons had at least one type of social media account. The most widely-used social media platform was LinkedIn (55\% of surgeons). 25\% of surgeons had a Facebook account and 31\% had a Research Gate profile. Nine percent of surgeons were on Twitter whilst less than $2 \%$ were on YouTube. There was no difference between the sexes in use of websites or uptake of social media. NZ surgeons were more engaged with LinkedIn than their Australian peers. Younger surgeons were more likely to use social media. Conclusion: Colorectal surgeons in Australia and NZ are users of multiple social media platforms and have a strong online presence. There is potential for further uptake of social media which could enhance surgeon-patient and surgeon-surgeon interaction and education.
\end{abstract}

Keywords: social media, internet, colorectal surgery, medical education

Cite This Article: Matija Radojcic, Michael Smits, Nilmini Wickramasinghe, Nathan Lawrentschuk, and Philip Smart, “Australasian Colorectal Surgeons in the Modern Era: The Rise of Social Media.” Global Journal of Surgery, vol. 6, no. 1 (2018): 1-5. doi: 10.12691/js-6-1-1.

\section{Introduction}

The internet era has forged a new approach to communication, allowing for instantaneous sharing and dissemination of information between users around the globe. At the forefront of this revolution has been social media, defined as "online environments where users contribute, receive and explore content primarily generated by fellow users” [1]. Examples of such platforms include Facebook, Twitter, ResearchGate, YouTube and LinkedIn, each of which occupy a certain niche and allow users to interact with each other in different ways (networking, blogging, photo sharing, etc.). The uptake of social media has expanded at a rapid rate; the average individual uses social media for 135 minutes daily [2], and Facebook claimed over 30.6 billion visits to its website in the month of November 2017 alone [3]. The medical profession has also embraced social media. Multiple surgical specialties are active on various platforms [4-9] and guidelines for social media use by doctors are now published by medical regulatory bodies around the world, including Australia and NZ [10,11].

The ways in which doctors use social media is multifaceted and includes both educational and commercial purposes. Social media can be used by surgeons to advertise to potential patients, educate the community on public health issues, and share their experiences with 'live tweets' during surgical conferences. Furthermore, in a country such as Australia with a significant geographical dispersal of medical practitioners, social media can provide an avenue for surgeons to communicate and share their views on new research and novel surgical techniques. Some authors have stated that social media is a necessary component of the practice of surgery [12].

Given the potential of social media to connect surgeons with patients and colleagues, we aimed to examine the online and social media presence of all currently practicing Australian and NZ colorectal surgeons. 


\section{Methodology}

All active members of the CSSANZ were identified via the CSSANZ website's 'Find a Surgeon' service during December 2017. Only surgeons working in Australia and NZ were included in the study.

A Google search was performed by using the surgeon's name followed by 'colorectal surgeon' to determine whether the surgeon had a private practice website. If a private practice website was found, the website was assessed as belonging to a single practitioner or as part of a group practice. Academic institutions and private or public hospitals which mentioned the surgeon by name were not included.

Surgeons were also searched for by name on Facebook, Twitter, LinkedIn, YouTube and ResearchGate. A profile was deemed as belonging to a surgeon only if the name matched fully and the profile identified as belonging to a colorectal surgeon, or if there was a verifiable photo of the surgeon. Twitter profiles were analysed for number of 'tweets', number of 'followers' and those 'following' the surgeon. Facebook profiles were categorised as 'public' (open to viewing by anyone) or 'private' (accessible only to 'friends' of the surgeon), as well as whether the Facebook profile was for personal or professional use. The number of LinkedIn posts and connections to other users were noted, as were the number of videos per YouTube account. Because LinkedIn connections are displayed as ' $>500$ ' once a user has more than 500 connections, those profiles were regarded as having 500 connections only. ResearchGate profiles were analysed for the number of 'followers' and the number of people 'following' the surgeon.

Other factors analysed included the sex of the surgeon, the number of years in practice, and the geographical location of the surgeon.

Data were tabulated using Microsoft Excel for Windows 2016 (Microsoft, Redmond, WA, USA) and statistical analysis was performed using SPSS version 20 (IBM, New York, NY, USA). $\mathrm{P}<0.05$ was considered to indicate statistical significance.

\section{Results}

There were 230 practicing colorectal surgeons in Australia and NZ as of December 2017. Every state excluding the Northern Territory (NT) was represented; there were no NT colorectal surgeons as per the CSSANZ website. Of the 230 identified surgeons, 184 (80\%) had a website, of which 147 (80\%) were 'group practice' websites featuring more than one surgeon. More Australian surgeons had a website than NZ surgeons (61\% vs $44 \%$, respectively) but this was not statistically significant $(\mathrm{p}=0.067)$.

One hundred and fifty six colorectal surgeons (68\%) had at least one type of social media account and there was an average of 1.2 social media accounts per surgeon. Australian surgeons had a mean 1.1 social media accounts while NZ surgeons had a mean 1.8. This difference was not statistically significant $(p=0.89)$. There were no surgeons using all five social media platforms investigated in this study (Table 2).
Fifty five percent of surgeons had a LinkedIn account, making it the most popular social media platform. Despite this, it appears surgeon activity on LinkedIn is low as only 5 surgeons had posted content on the website. There was an average of 141.5 connections to other LinkedIn profiles per surgeon and $11.8 \%$ of surgeons had more than 500 connections. There was no difference in LinkedIn uptake between Australian and NZ surgeons ( $p=0.06)$.

A total of 58 surgeons (25\%) had a Facebook account, of which 46 were private and not accessible to the public. Six of the total Facebook accounts (10\%) were business-related.

Seventy one surgeons (31\%) had a ResearchGate profile with an average of 44 followers per account. Each surgeon was following an average of 25 other Research Gate accounts. New Zealand surgeons were more likely to have a ResearchGate profile than Australian surgeons ( $\mathrm{p}=$ 0.0004), but there were no further differences between the countries, including mean number of social media accounts per surgeon.

Twitter uptake was relatively low compared to other platforms. Only 20 surgeons (9\%) had a Twitter account, with an average of 204 tweets, 94 followers and 73 accounts being followed. Despite a relatively higher proportion of NZ surgeons using Twitter compared to their Australian colleagues (14\% vs $8 \%$, respectively), this difference was not statistically significant $(\mathrm{p}=0.23)$.

YouTube was a relatively unpopular social media platform, with only 4 surgeons possessing an account. However, these surgeons appear to be active users, having posted an average of 33 videos each. 35 surgeons (15\%) surgeons had no online presence whatsoever, with no personal website or social media account.

There were 201 male and 29 female colorectal surgeons, who had a near-equal mean number of social media accounts per surgeon (1.2 and 1.3, respectively). Surgeons newer to practice were more likely to be more engaged in social media. Those practicing for 10-19 years had a significantly higher mean number of social media accounts than those practicing for 20-29 years $(p=0.003)$ and $40-49$ years $(p=0.034)$ (Figure 1$)$. There were no significant differences between the other age groups.

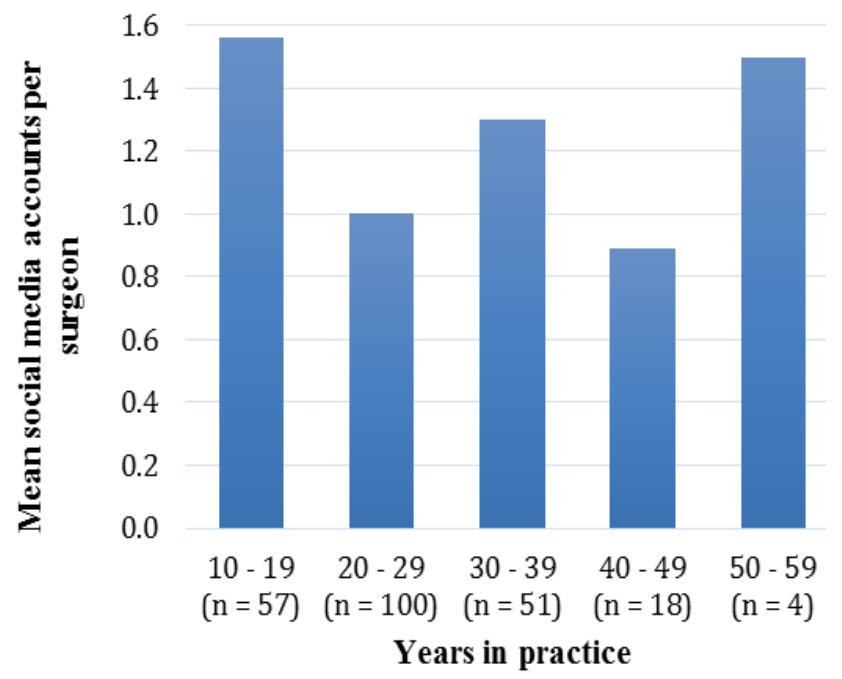

Figure 1. Average number of social media accounts per surgeon as related to years in practice. ( $\mathrm{n}=$ total number of surgeons) 
Table 1. Number and percentage of colorectal surgeons in each state/territory and country using each form of social media

\begin{tabular}{|c|c|c|c|c|c|c|c|c|c|c|c|}
\hline \multirow{2}{*}{ State/Territory/Country } & \multicolumn{2}{|c|}{ Twitter } & \multicolumn{2}{|c|}{ Facebook } & \multicolumn{2}{|c|}{ LinkedIn } & \multicolumn{2}{|c|}{ YouTube } & \multicolumn{2}{|c|}{ ResearchGate } & \multirow{2}{*}{$\begin{array}{c}\text { Total colorectal } \\
\text { surgeons }\end{array}$} \\
\hline & $\mathrm{N}$ & $\%$ & $\mathrm{~N}$ & $\%$ & $\mathrm{~N}$ & $\%$ & $\mathrm{~N}$ & $\%$ & $\mathrm{~N}$ & $\%$ & \\
\hline NSW & 7 & $10 \%$ & 17 & $24 \%$ & 40 & $56 \%$ & 2 & $3 \%$ & 21 & $30 \%$ & 71 \\
\hline VIC & 4 & $7 \%$ & 13 & $24 \%$ & 31 & $57 \%$ & 0 & $0 \%$ & 19 & $35 \%$ & 54 \\
\hline QLD & 1 & $3 \%$ & 5 & $17 \%$ & 15 & $50 \%$ & 1 & $3 \%$ & 4 & $13 \%$ & 30 \\
\hline WA & 2 & $15 \%$ & 1 & $8 \%$ & 5 & $39 \%$ & 0 & $0 \%$ & 2 & $15 \%$ & 13 \\
\hline SA & 1 & $5 \%$ & 5 & $25 \%$ & 10 & $50 \%$ & 0 & $0 \%$ & 5 & $25 \%$ & 20 \\
\hline TAS & 0 & $0 \%$ & 4 & $80 \%$ & 1 & $20 \%$ & 0 & $0 \%$ & 0 & $0 \%$ & 5 \\
\hline ACT & 0 & $0 \%$ & 0 & $0 \%$ & 0 & $0 \%$ & 0 & $0 \%$ & 0 & $0 \%$ & 1 \\
\hline NT & 0 & $0 \%$ & 0 & $0 \%$ & 0 & $0 \%$ & 0 & $0 \%$ & 0 & $0 \%$ & 0 \\
\hline Australia & 15 & $8 \%$ & 45 & $23 \%$ & 102 & $53 \%$ & 3 & $2 \%$ & 51 & $26 \%$ & 194 \\
\hline New Zealand & 5 & $14 \%$ & 13 & $36 \%$ & 25 & $69 \%$ & 1 & $3 \%$ & 20 & $56 \%$ & 36 \\
\hline All & 20 & $9 \%$ & 58 & $25 \%$ & 127 & $55 \%$ & 4 & $2 \%$ & 71 & $31 \%$ & 230 \\
\hline
\end{tabular}

Table 2. Number and mean social media platforms used by surgeons in each state/territory and country

\begin{tabular}{|c|c|c|c|c|c|c|c|c|}
\hline \multirow[t]{2}{*}{ State/Territory/Country } & \multicolumn{6}{|c|}{$\begin{array}{c}\text { Number of social media accounts } \\
\text { (Twitter, Facebook, LinkedIn, YouTube, ResearchGate) }\end{array}$} & \multirow{2}{*}{$\begin{array}{l}\text { Mean social } \\
\text { media level }\end{array}$} & \multirow{2}{*}{$\begin{array}{l}\text { Total colorectal } \\
\text { surgeons }\end{array}$} \\
\hline & 0 & 1 & 2 & 3 & 4 & 5 & & \\
\hline NSW & 23 & 24 & 12 & 9 & 3 & 0 & 1.23 & 71 \\
\hline VIC & 18 & 11 & 19 & 6 & 0 & 0 & 1.24 & 54 \\
\hline QLD & 12 & 11 & 6 & 1 & 0 & 0 & 0.87 & 30 \\
\hline WA & 7 & 3 & 2 & 1 & 0 & 0 & 0.77 & 13 \\
\hline SA & 7 & 8 & 3 & 1 & 1 & 0 & 1.05 & 20 \\
\hline TAS & 1 & 3 & 1 & 0 & 0 & 0 & 1 & 5 \\
\hline ACT & 0 & 0 & 0 & 0 & 0 & 0 & 0 & 1 \\
\hline NT & 0 & 0 & 0 & 0 & 0 & 0 & 0 & 0 \\
\hline Australia & 68 & 60 & 43 & 18 & 4 & 0 & 1.11 & 194 \\
\hline New Zealand & 5 & 7 & 18 & 3 & 3 & 0 & 1.78 & 36 \\
\hline All & 73 & 67 & 61 & 21 & 7 & 0 & 1.22 & 230 \\
\hline
\end{tabular}

\section{Discussion}

Our data demonstrate that the majority of Australian and NZ colorectal surgeons (68\%) are using at least one form of social media. This rate is comparable to Australian and NZ urologists (70.1\%) [5] and the Australian medical community in general (75\% of doctors) [13]. United Kingdom (UK) plastic surgeons had a relatively high uptake of social media which increased significantly from 2011 to 2013 (a rise from 36\% to 82\%) [7]. This rise demonstrates the growing popularity of social media use amongst surgeons and is a trend that is likely to continue in coming years.

The most popular social media platform (55\% of surgeons) was LinkedIn, an employment-oriented networking website. LinkedIn profiles typically consist of a user's curriculum vitae and personal photo, and enables members to make "connections" to each other in an online network which may represent real-world professional relationships. The website also facilitates the creation of surgery-related groups, allowing users to share information and stay abreast of new developments. LinkedIn profiles are typically accessible to the general public and can also serve as a tool for surgeons to advertise to potential patients, in similar fashion to a personal website. These aspects of LinkedIn may play a role in its popularity, although this remains unclear with the data from the present study. Australian and NZ colorectal surgeons demonstrated a higher uptake of LinkedIn use compared to their UK counterparts, of which only $37.1 \%$ had a LinkedIn account [8]. Other surgical specialties had comparable rates to those in our study: $46 \%$ of UK vascular surgeons [4], 51.3\% of Australian and NZ urologists [5] and 52\% of UK plastic surgeons [7] used LinkedIn.

Twitter, a 'microblogging' platform where users interact with each other by posting short messages in a public forum, is fast becoming an important platform for connecting surgeons and disseminating information. In 2016, a Twitter social media campaign promoting the hashtag \#colorectalsurgery was launched with the aim of providing a specialty-specific forum to collate discussions and science relevant to the global colorectal community [14]. Within 24 weeks, the campaign garnered more than 1600 Twitter users and more than 12000 tweets. Most colorectal surgery-themed journals now have active Twitter accounts such as Colorectal Disease (@colorectaldis), Diseases of the Colon and Rectum (@DCRjournal) and Techniques in Coloproctology (@TechColoproctol) [15]. Major international conferences such as the American Society of Colon and Rectal Surgeons (ASCRS) Annual Scientific Meeting and the Annual Scientific Meeting of the European Society of Coloproctology (ESCP) had their own conference hashtags, \#ASCRS17 and \#ESCP17 respectively. Furthermore, there is evidence to suggest that conference-related tweets can predict future citations in journals $[16,17]$. Twitter also made an impact on the surgical community and society at large with the 2017 
\#ilooklikeasurgeon movement, which encouraged women and other minority groups in the male-dominated profession to be visible by posting photos of themselves with the aforementioned hashtag. Less than one in ten of surgeons in our study had a Twitter account and Twitter use was also low in UK colorectal surgeons (3.1\%) [8]. This is in contrast to other surgical specialties such as urologists [5] and plastic surgeons [7] who had a 33.3\% and 22\% uptake of Twitter among their surgeons, respectively. Given the many roles Twitter plays in surgical communication, it may be beneficial for Australian and NZ colorectal surgeons to increase their engagement with this platform.

ResearchGate is a site for scientists and researchers to share papers, ask and answer questions, and find collaborators. According to a study by Nature it is the largest academic social network in terms of active users [18]. The majority of colorectal surgeons in NZ use ResearchGate, while only a quarter of Australian surgeons do so. The reasons for this are unclear, but the lower overall number and relative geographical isolation of NZ colorectal surgeons may drive them online to discuss research and look for collaborators.

Surgical education is also being enhanced by social media. Ibrahim at el report that social media outlets provide a valuable platform for surgeons to collaborate and plan for difficult operative cases [19], and Carter et al state that video-based peer feedback through social networking accelerates the robotic surgery learning curve during simulation [20]. Closed-membership Facebook groups such as the International Hernia Collaboration [21] and Robotic Surgery Collaboration [22] have gained popularity as they provide surgeons with an opportunity to present (de-identified) cases, ask questions, offer suggestions, and gather peers' experiences with similar cases or challenges [19]. Only 25\% of Australian and NZ colorectal surgeons were identified as having a Facebook account, and are potentially missing out on an important educational resource.

A further aspect of social media use in surgery is its commercial application. A surgeon may create a business-related social media profile to reach a larger number of potential patients. Social media can then provide a rapid, direct way to communicate with patients. However, a potential pitfall is that patients may become overly-reliant on social media, seeing it as a substitute for face-to-face consultations with surgeons, possibly leading to delays in diagnoses and treatment. Multiple other hazards related to social media use exist. Doctors are warned that inappropriate use of social media can result in harm to patients and the profession, including breaches of confidentiality, defamation of colleagues or employers, and violation of doctor-patient boundaries. The professional integrity of doctors and medical students can also be damaged through problematic interprofessional online relationships, and unintended exposure of personal information to the public, employers or universities [23]. Surgeons need to exercise caution be aware of the social media policies of their institutions and professional bodies in order to protect themselves online.

Our data set is unique as it provides a real-world look at social media use by colorectal surgeons in Australia and NZ. The ease of access to the information gives a realistic idea of what a member of the general public might find if they were attempting to gather information about their colorectal surgeon. Furthermore, our study utilises freely-available data gathered directly from online sources and is free from bias. The project was limited by the constraints of internet web searches; some surgeons employ enhanced privacy settings, meaning that they could not be identified without a direct connection to their account. Another commonly-encountered limitation was that of the surgeon with the 'common' name. A social media search for 'John Smith', for example, may yield thousands of hits and make it difficult to pinpoint the exact individual. However, these challenges provide an accurate representation of what it might be like for a member of the public to seek out a colorectal surgeon online.

While our study demonstrates the uptake of social media among colorectal surgeons, there is lack of data on how surgeons are using social media. Only limited information was gleaned regarding activity on social media; a survey of the nature of social media use among colorectal surgeons would provide a useful adjunct to our data set. Because the data collected in this study is accessible by simple web searches, the study is easily reproducible and could be conducted again in a number of years to determine whether the uptake of social media amongst colorectal surgeons was increasing.

\section{Conclusion}

Colorectal surgeons in Australia and NZ are users of multiple different social media platforms, and a significant proportion of surgeons utilise private or group websites to promote their practice. Younger surgeons are more involved with social media than their older peers and LinkedIn is the most utilised social media platform. Given the potential for both educational and commercial benefits of social media use, it is of benefit for colorectal surgeons to keep pace with this ever-evolving technology.

\section{Acknowledgements}

The authors do not wish to make any acknowledgements.

\section{References}

[1] McGowan B.S., Wasko M., Vartabedian B.S., Miller R.S., Freiherr D.D., Abdolrasulnia M., "Understanding the factors that influence the adoption and meaningful use of social media by physicians to share medical information," J Med Internet Res, 14 (5). 117. Sep. 2012.

[2] Statista, "Global time spent on social networking by internet users worldwide from 2012 to 2017,"

https://www.statista.com/statistics/433871/daily-social-mediausage-worldwide/ (accessed December 2017).

[3] Similar Web, "November 2017 Overview,” https://www.similarweb.com/website/facebook.com (accessed December 2017).

[4] Cochrane A.R., McDonald J.J., Brady R.R., "Social media use among United Kingdom Vascular Surgeons: A Cross-Sectional Study,” Ann Vasc Surg, 33. 252-7. May. 2016.

[5] Davies N., Murphy D.G., van Rij S., Woo H.H., Lawrentschuk N., "Online and social media presence of Australian and New Zealand urologists,” BJU Int, 116 (6). 984-9. Dec. 2015. 
[6] Lui D.H., McDonald J.J., de Beaux A., Tulloh B., Brady R.R.W., "Contemporary engagement with social media amongst hernia surgery specialists,” Hernia, 21 (4). 509-515. Aug. 2017.

[7] Mabvuure N.T., Rodrigues J., Klimach S., Nduka C., "A cross-sectional study of the presence of United Kingdom (UK) plastic surgeons on social media," J Plast Reconstr Aesthet Surg, 67 (3). 362-7. Mar. 2014.

[8] McDonald J.J., Bisset C., Coleman M.G., Speake D., Brady R.R., "Contemporary use of social media by consultant colorectal surgeons," Colorectal Dis, 17 (2). Feb. 2015.

[9] McEvenue G., Copeland A., Devon K.M., Semple J.L., "How Social Are We? A Cross-Sectional Study of the Website Presence and Social Media Activity of Canadian Plastic Surgeons," Aesthet Surg J, 36 (9). Oct. 2016.

[10] Australian Medical Association, "Social Media and the Medical Profession. A guide to online professionalism for medical practitioners and medical students,"

https://ama.com.au/system/tdf/documents/Social_Media_and_the_ Medical_Profession_FINAL_with_links_0.pdf?file=1\&type=node \&id=35198 (Accessed December 2017).

[11] Medical Council of New Zealand, "Statement on use of the internet and electronic communication," https://www.mcnz.org.nz/assets/News-and-

Publications/Statement-on-use-of-the-internet-and-electroniccommunication-v2.pdf (Accessed December 2017).

[12] Steele S.R., Arshad S., Bush R., Dasani S., Cologne K., Bleier J.I., Raphaeli T., Kelz R.R., "Social media is a necessary component of surgery practice,” Surgery, 158 (3). Sep. 2015.

[13] Brown J., Ryan C., Harris A., "How doctors view and use social media: a national survey,” J Med Internet Res, 16 (12). 267. Dec. 2014.
[14] Brady R.R.W., Chapman S.J., Atallah S., Chand M., Mayol J., Lacy A.M., Wexner S.D., “\#colorectal surgery,” Br J Surg, 104 (11). 1470-1476. Oct. 2017.

[15] Wexner S.D., Petrucci A.M., Brady R.R., Ennis-O'Connor M., Fitzgerald J.E., Mayol J., "Social media in colorectal surgery," Colorectal Dis, 19 (2). 105-114. Feb. 2017.

[16] Eysenbach G., "Can tweets predict citations? Metrics of social impact based on Twitter and correlation with traditional metrics of scientific impact,” J Med Internet Res, 13 (4). 23. Dec. 2011.

[17] Peoples B.K., Midway S.R., Sackett D., Lynch A., Cooney P.B. "Twitter Predicts Citation Rates of Ecological Research," PLoS One, 11 (11). e0166570. Nov. 2016.

[18] Van Noorden R., "Online collaboration: Scientists and the social network,” Nature, 512 (7513). 126-9. Aug. 2014.

[19] Ibrahim A.M., Varban O.A., Dimick J.B., "Novel uses of video to accelerate the surgical learning curve," $J$ Laparoendosc Adv Surg Tech A, 26 (4). 240-2. Apr. 2016.

[20] Carter S.C., Chiang A., Shah G., Kwan L., Montgomery J.S., Karam A., Tarnay C., Guru K.A., Hu J.C., "Video-based peer feedback through social networking for robotic surgery simulation: a multicenter randomized controlled trial,” Ann Surg, 261 (5). 870-5. May. 2015.

[21] Jacob B.P., "International Hernia Collaboration,” Facebook, www.facebook.com/groups/herniacollab/. Published 2012. (Accessed December 2017)

[22] Kudsi O.Y. "R,obotic Surgery Collaboration.,” Facebook, www.facebook.com/groups/15227779313.38325/(Accessed December 2017).

[23] Mansfield S.J., Morrison S.G., Stephens HO, Bonning M.A., Wang S.H., Withers A.H., Olver R.C., Perry A.W., "Social media and the medical profession,” Med J Aust, 194 (12). 624-4. Jun. 2011. 